\title{
Influence of Particles Size on NIR Spectroscopic Estimations of Charcoal Properties
}

\author{
Fernanda Maria Guedes Ramalho ${ }^{1}$ (D), Rodrigo Simetti ${ }^{1}$ (D), \\ Taiana Guimarães Arriel ${ }^{1}$ (D), Breno Assis Loureiro ${ }^{1}$ (D), \\ Paulo Ricardo Gherardi Hein ${ }^{1}$ (D) \\ ${ }^{1}$ Departamento de Ciências Florestais, Universidade Federal de Lavras - UFLA, Lavras/MG, Brasil
}

\begin{abstract}
The objective of this study was to evaluate the influence of particle size of charcoal samples on the predictive model statistics of charcoal chemical composition based on the NIR spectroscopy. Spectra of Acacia and of Eucalyptus charcoal were collected in the 100, 60 and 40 mesh granulometry, besides the powder remaining at the bottom of the sieves sets. They were subjected to principal component analysis and partial least square regression in order to estimate of volatile material (VMC), ash (AC) and fixed carbon content (FCC) values. The estimation of the FCC, VMC and AC of Eucalyptus based on NIR was more accurate using spectra of lower-particle-size powder. The models for Acacia charcoal were better using spectra measured at 40 mesh to predict FCC, 100 mesh for AC, and smaller size for VMC. NIR spectroscopy was efficient in estimating the immediate chemical composition of charcoal, except for AC.
\end{abstract}

Keywords: wood pyrolysis, NIR, proximate chemical analysis, forest biomass. 


\section{INTRODUCTION}

Charcoal is an alternative to add value to wood by turning it into a highly energetic and carbon-rich product. Carbonization increases the calorific value and the fixed carbon content of the wood, making the product a more energy-intensive material when compared to the raw material from which it originated (Trugilho et al., 2001). During the carbonization process, the wood is subjected to the action of high temperatures in the transformation process in which its chemical components are extensively modified (Akhtar et al., 2018).

Variation in the chemical composition of charcoal influences its performance in industrial use (Vilela et al., 2014). Therefore the study of the chemical properties of charcoal is of great interest for a more rational use of this key input by most Brazilian steelmakers (Protásio et al., 2011). The fixed carbon content, volatile materials and ash content has a considerable influence on the energetic use of the biofuel, since they have significant correlation with the calorific value of charcoal (Majumder et al., 2008; Parikh et al., 2005).

In general, fuels with high fixed carbon content burn more slowly, resulting in longer residence times in the furnace, compared to materials with low fixed carbon content (Vale et al., 2001). Moreover, the fixed carbon of charcoal affects the pig iron production process: the higher the fixed carbon content the greater the mass quantity of this compound inside the blast furnace, improving the use of its internal space during the thermoreduction (Barbieri et al., 2016).

Assessing and monitoring the quality of charcoal is a challenge for companies that use charcoal in their production process, such as steel industries. Charcoal properties are commonly determined by conventional methods, but are time-consuming and require sample preparation. In order to obtain greater agility and precision, near infrared (NIR) spectroscopy has been successfully applied to analyze the properties of a large number of materials. The technology makes it possible to save reagents to determine various properties, besides reducing cost and time spent in routine laboratory analyses (Diesel et al., 2014; Pasquini, 2018).

NIR spectroscopy has been used in charcoal evaluations by means of qualitative analyses, such as the differentiation of carbonization processes (Monteiro et al., 2010) and the distinction of charcoals produced by different forest species (Davrieux et al., 2010; Muniz et al., 2013; Nisgoski et al., 2015a; Ramalho et al., 2017). Moreover, the technique can be used in quantitative approaches for predicting several charcoal properties such as moisture content, volatile matter content, fixed carbon content, ash content (Barbosa et al., 2013), apparent relative density and gravimetric yield (Costa et al., 2018). However, the influence of the charcoal granulometry on the accuracy of chemical properties estimates based on near infrared radiation is unknown. Therefore, the objective of this study was to evaluate the effect of powder granulometry on the performance of chemical properties predictive models based on the near infrared spectra of charcoal.

\section{MATERIAL AND METHODS}

\subsection{Origin of material}

Twenty samples of Acacia mangium and twenty samples of Eucalyptus urophylla $\times$ E. grandis hybrid with 54 months of age from the municipality of Montes Claros, northern region of the state of Minas Gerais, Brazil (16 $44^{\prime} 06^{\prime \prime}$ south and $43^{\circ} 51^{\prime} 43^{\prime \prime}$ west) were investigated in this study. Wood discs (thickness: $30 \mathrm{~mm}$ ) were collected at $0 \%$ of the commercial height of the trees and divided into 4 wedges passing through the pith. Two opposing wedges (defect free) were used for charcoal production.

\subsection{Carbonization of wood}

Wood carbonization was carried out in a muffle-type laboratory electric oven connected to a water-cooled condenser, which is coupled to the non-condensible gas collecting flask. Before carbonization the wood samples were oven dried at $103^{\circ} \mathrm{C} \pm 2{ }^{\circ} \mathrm{C}$ and introduced into a cylindrical metal reactor (length: $30 \mathrm{~cm}$ and diameter: $12 \mathrm{~cm}$ ). The total pyrolysis time was approximately 4 hours with a heating rate of $1.67^{\circ} \mathrm{C} / \mathrm{min}$. The pyrolysis started at $100^{\circ} \mathrm{C}$ and ran up to the final temperature of $4500^{\circ} \mathrm{C}$, with a residence time of 30 minutes.

\subsection{Charcoal characterization and sample preparation}

Proximate chemical analysis was carried out in order to determine the volatile material content (VMC) and ash contents (AC). The fixed carbon content (FCC) was 
calculated by difference according to the procedure described in ASTM D1762-84 (ASTM, 2007).

Charcoal pieces were reduced to particles with granulometries of 40,60 and 100 mesh by the use of vibrating sieves. The finest material remaining in the sieve was also collected.

\subsection{NIR spectra acquisition}

Near infrared (NIR) spectra were recorded on charcoal samples of different granulometries using a Fourier transformed NIR spectrometer (Bruker Optik GmbH, model: MPA, Ettlingen, Germany) using an integrating sphere. NIR spectra acquisition was performed on the charcoal samples of different particle sizes in glass containers (vials) by means of OPUS version 7.5 software. The spectral range of 12500 to $4000 \mathrm{~cm}^{-1}$ was used, with a resolution of $8 \mathrm{~cm}^{-1}$ in diffuse reflection mode.

\subsection{Multivariate statistical analyses of data}

Statistical analyses were performed using Chemoface v.1.61 software (Nunes et al., 2012). Principal component analysis (PCA) was performed with the purpose of previously exploring the data dependence. Partial least squares (PLS) regression was adjusted based on the NIR spectra (matrix X) and the fixed carbon, ash and volatile material content values as dependent variables (matrix Y). The models were adjusted from untreated spectra data and after mathematical treatments such as first derivative (13-point filter and a second order polynomial), normalization and standard normal variate (SNV). PLS regression models were evaluated by the mean square error (RMSE) and the coefficient of determination $\left(\mathrm{R}^{2}\right)$ between laboratory determined and NIR predicted values.

\section{RESULTS AND DISCUSSION}

\subsection{NIR spectra on charcoal}

The mean untreated NIR spectral signature of Acacia and Eucalyptus charcoal samples of different particle sizes (40, 60, 100 mesh and fine) is shown in Figure 1. As the particle size reduces, the average NIR absorbance also decreases; however the absorption bands are the same, independent of particle size. This behavior was previously reported by Nisgoski et al. (2015b), who investigated the effect of granulometry on NIR absorbance in Salix sp.

NIR spectra ranging from 12500 to $9000 \mathrm{~cm}^{-1}$ presented high noise (Figure 1). Costa et al. (2018) have studied Eucalyptus charcoal through NIR and also observed this tendency. The spectra plot does not allow verifying if there are differences between the charcoals according to the granulometry. That is why it is necessary to use multivariate statistical analysis to identify such possible differences.

\subsection{Multivariate analyses}

Principal component analyses (PCA) was performed separately for the two species: the first two PC together accounted for $99.99 \%$ of the data variation for Acacia and $99.90 \%$ for Eucalyptus. PCA scores of the Acacia

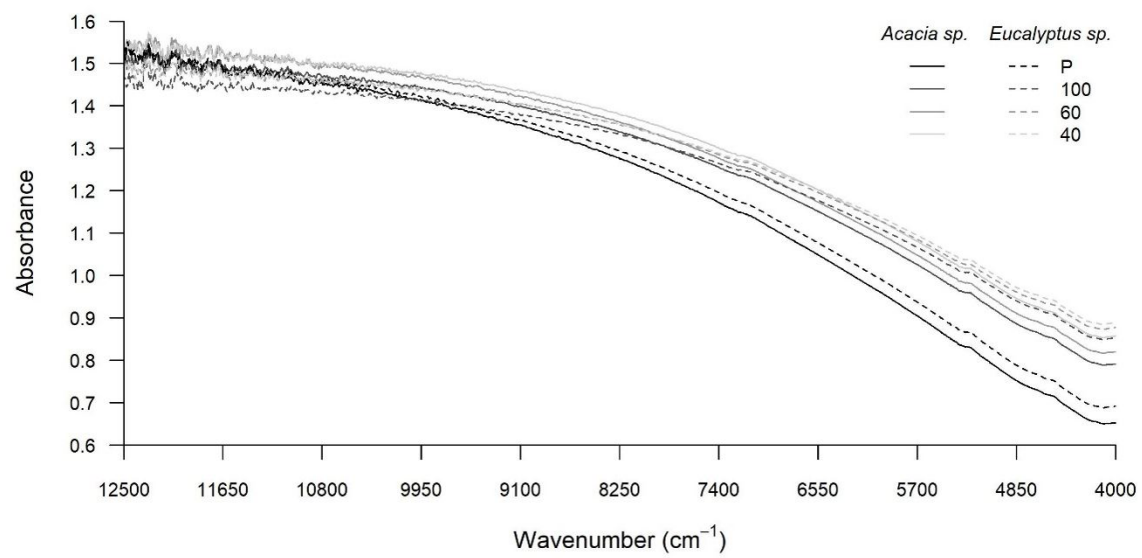

Figure 1. Diffuse reflection spectra shown as original data for Eucalyptus and Acacia charcoal milled at 100, 60, 40 mesh and fine powder $(\mathrm{P})$. 
(Figure 2A) and Eucalyptus (Figure 2B) charcoal spectra in different granulometries were not clearly divided into groups according to the particle size of samples because the chemical composition of charcoal is the same within each species. However, the scores containing information on the fine powder spectra
(P) showed a tendency to separate from the others. Fahey et al. (2018) reported that although there is influence of particle size on NIR acquisition, the effect of this variable is small. Thus, it is difficult to observe the grouping of samples in function of this characteristic.
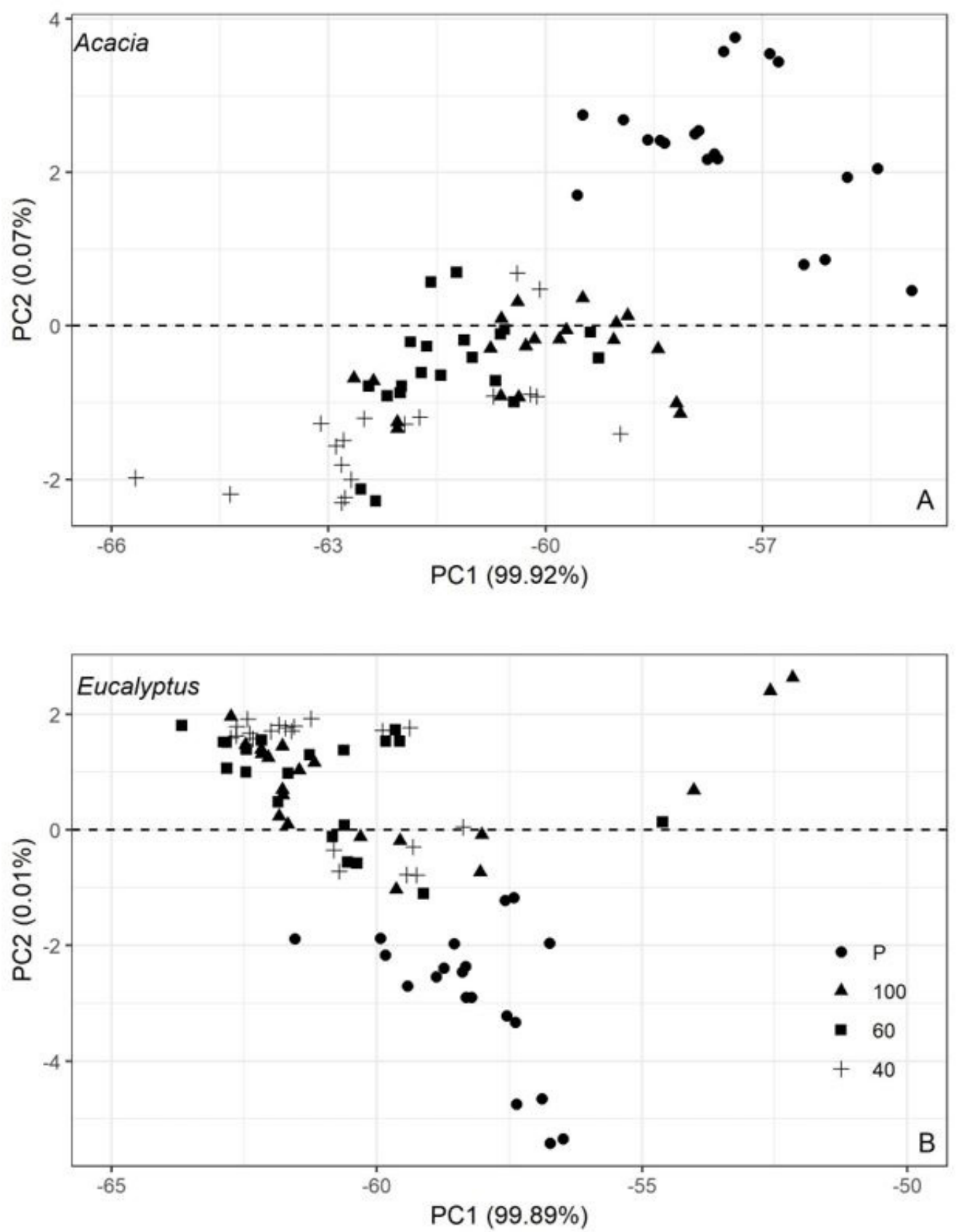

Figure 2. Scores of PCA applied to NIR spectra recorded on charcoal powder milled at 100, 60, 40 mesh and fine powder (P) for Acacia (A) and Eucalyptus (B) charcoal. 
The statistics of PLS regressions for estimating volatile matter (VMC), ash (AC) and fixed carbon (FCC) content according to the species and particle size are presented in Table 1. The coefficient of determination for the calibration $\left(\mathrm{R}^{2} \mathrm{c}\right)$ was over 0.99 in all models. Root mean square error for calibration (RMSEc) ranged from 0.000 to 0.046 , whereas the variation was broader for cross validation. The $\mathrm{R}^{2} \mathrm{cv}$ values ranged from 0.032 to 0.842 , with the RMSEcv ranging from 0.058 to 1706 in the cross-validations. The model based on charcoal spectra from the fine powder (P) showed the highest $\mathrm{R}^{2} \mathrm{cv}$. However, these statistics are lower than those reported by Costa et al.
(2018), which presented an $\mathrm{R}^{2} \mathrm{cv}$ of 0.96 in calibrations using untreated NIR spectra of Eucalyptus charcoal.

The PLS-R model for estimating ash content that yielded the best coefficient of determination was obtained in the finer grain size for Euclyptus ( $\mathrm{R}^{2} \mathrm{cv}$ of 0.375$)$, whereas the 100 mesh powdered spectra resulted in higher correlation $\left(\mathrm{R}^{2} \mathrm{cv}\right.$ of 0.353$)$ for Acacia. However, all parameters of the Ash models did not obtain satisfactory values. Ash is composed of inorganic materials such as minerals and the near infrared spectroscopy is indicated only for organic materials.

In order to estimate the volatile material content (VMC), the PLS-R models with higher $\mathrm{R}^{2} \mathrm{cv}$ were obtained

Table 1. Statistics for volatile matter (VMC), ash (AC) and fixed carbon (FCC) content models developed from NIR spectra recorded on charcoal powder milled at 100, 60 and 40 mesh and fine powder (P) for Acacia and Eucalyptus charcoal.

\begin{tabular}{|c|c|c|c|c|c|c|}
\hline \multirow{2}{*}{ Statistics } & \multicolumn{3}{|c|}{ Acacia } & \multicolumn{3}{|c|}{ Eucalyptus } \\
\hline & VMC & AC & FCC & VMC & AC & FCC \\
\hline \multicolumn{7}{|c|}{ Fine Powder } \\
\hline Treat & Raw & Norm & Raw & Norm & Raw & Norm \\
\hline LV & 6 & 6 & 7 & 6 & 5 & 6 \\
\hline RMSEc & 0.013 & 0.001 & 0.003 & 0.005 & 0.002 & 0.005 \\
\hline $\mathrm{R}^{2} \mathrm{cal}$ & 1.000 & 1.000 & 1.000 & 1.000 & 0.999 & 1.000 \\
\hline RMSEcv & 0.946 & 0.191 & 0.945 & 0.885 & 0.058 & 0.904 \\
\hline $\mathrm{R}^{2} \mathrm{cV}$ & 0.682 & 0.215 & 0.640 & 0.842 & 0.375 & 0.828 \\
\hline \multicolumn{7}{|c|}{ Powder 100 mesh } \\
\hline Treat & Norm & 1d & Norm & Raw & 1d & Raw \\
\hline LV & 6 & 8 & 4 & 6 & 6 & 6 \\
\hline RMSEc & 0.004 & 0.000 & 0.034 & 0.017 & 0.002 & 0.046 \\
\hline $\mathrm{R}^{2} \mathrm{cal}$ & 1.000 & 1.000 & 1.000 & 1.000 & 0.999 & 1.000 \\
\hline RMSEcv & 1.174 & 0.170 & 1.021 & 1.706 & 0.096 & 1.290 \\
\hline $\mathrm{R}^{2} \mathrm{cV}$ & 0.507 & 0.353 & 0.573 & 0.451 & 0.070 & 0.650 \\
\hline \multicolumn{7}{|c|}{ Powder 60 mesh } \\
\hline Treat & Norm & Raw & Norm & Norm & 1d & Norm \\
\hline LV & 7 & 7 & 7 & 5 & 6 & 7 \\
\hline RMSEc & 0.001 & 0.000 & 0.001 & 0.017 & 0.002 & 0.002 \\
\hline $\mathrm{R}^{2} \mathrm{cal}$ & 1.000 & 1.000 & 1.000 & 1.000 & 0.999 & 1.000 \\
\hline RMSEcv & 1.138 & 0.215 & 1.031 & 1.706 & 0.096 & 1.651 \\
\hline $\mathrm{R}^{2} \mathrm{cV}$ & 0.468 & 0.032 & 0.524 & 0.451 & 0.070 & 0.461 \\
\hline \multicolumn{7}{|c|}{ Powder 40 mesh } \\
\hline Treat & Norm & Raw & Norm & Norm & 1d & Norm \\
\hline LV & 6 & 6 & 6 & 5 & 6 & 6 \\
\hline RMSEc & 0.009 & 0.005 & 0.004 & 0.028 & 0.002 & 0.010 \\
\hline $\mathrm{R}^{2} \mathrm{cal}$ & 1.000 & 1.000 & 1.000 & 1.000 & 1.000 & 1.000 \\
\hline RMSEcv & 1.022 & 0.319 & 0.839 & 1.453 & 0.069 & 1.402 \\
\hline $\mathrm{R}^{2} \mathrm{cv}$ & 0.627 & 0.171 & 0.725 & 0.583 & 0.129 & 0.596 \\
\hline
\end{tabular}

LV: Latent Variables; RMSEc: Mean square error for calibration; $\mathrm{R}^{2}$ cal: Coefficient of determination for calibration; RMSEcv: Mean square error for cross validation; $\mathrm{R}^{2} \mathrm{cv}$ : Coefficient of determination for cross validation; Raw: Untreated spectra data; $1 \mathrm{~d}$ : first derivative; Norm: Normalization. 
using NIR spectra recorded on the fine powder, either in Eucalyptus ( $\mathrm{R}^{2} \mathrm{cv}$ of 0.842 ) or Acacia $\left(\mathrm{R}^{2} \mathrm{cv}\right.$ of 0.682$)$ charcoal. The PLS-R models for fixed carbon content from spectra of the fine powder also presented higher $\mathrm{R}^{2} \mathrm{cv}$ (0.828) for Eucalyptus. Andrade et al. (2012) presented $\mathrm{R}^{2} \mathrm{cv}$ values in the prediction of the fixed carbon content and content of volatile materials for Eucalyptus between 0.86 and 0.91 , respectively. In regard to Acacia models, NIR spectra taken from 40-mesh charcoal generated the highest $\mathrm{R}^{2} \mathrm{cv}$ model (0.725), as shown in Table 1. These findings showed the same trend probably because the values of volatile material content were used for the calculation of the fixed carbon content. To sum up, our findings suggest that charcoal milled at finer particle size is indicated for NIR spectral acquisition and prediction of this property.

PLS-R models developed from NIR spectra mathematically treated by normalization yielded better results, followed by models from untreated spectra. Most models were better using normalization for predicting FCC and VMC while estimates of AC should be performed from models based on untreated signal or spectra treated by first derivative. Andrade et al. (2012) reported higher $\mathrm{R}^{2}$ values for prediction of the FCC, VMC and gravimetric charcoal yield (GCY) using untreated NIR spectra of Eucalyptus. Costa et al. (2018) also found better statistics for estimating GCY, apparent relative density and final temperature carbonization of solid charcoal specimens using untreated NIR signals.

The lab-measured and NIR-predicted values plot (Figure 3 ) for the fixed carbon content according to particle size allows one to observe that there was no strong association between the values for the Eucalyptus and Acacia samples. Leave-one-out cross-validated PLS-R models for FCC in Acacia charcoal based on NIR spectra recorded on charcoal milled at 60 mesh presented the worst statistics $\left(\mathrm{R}^{2} \mathrm{cv}=0.461\right)$.
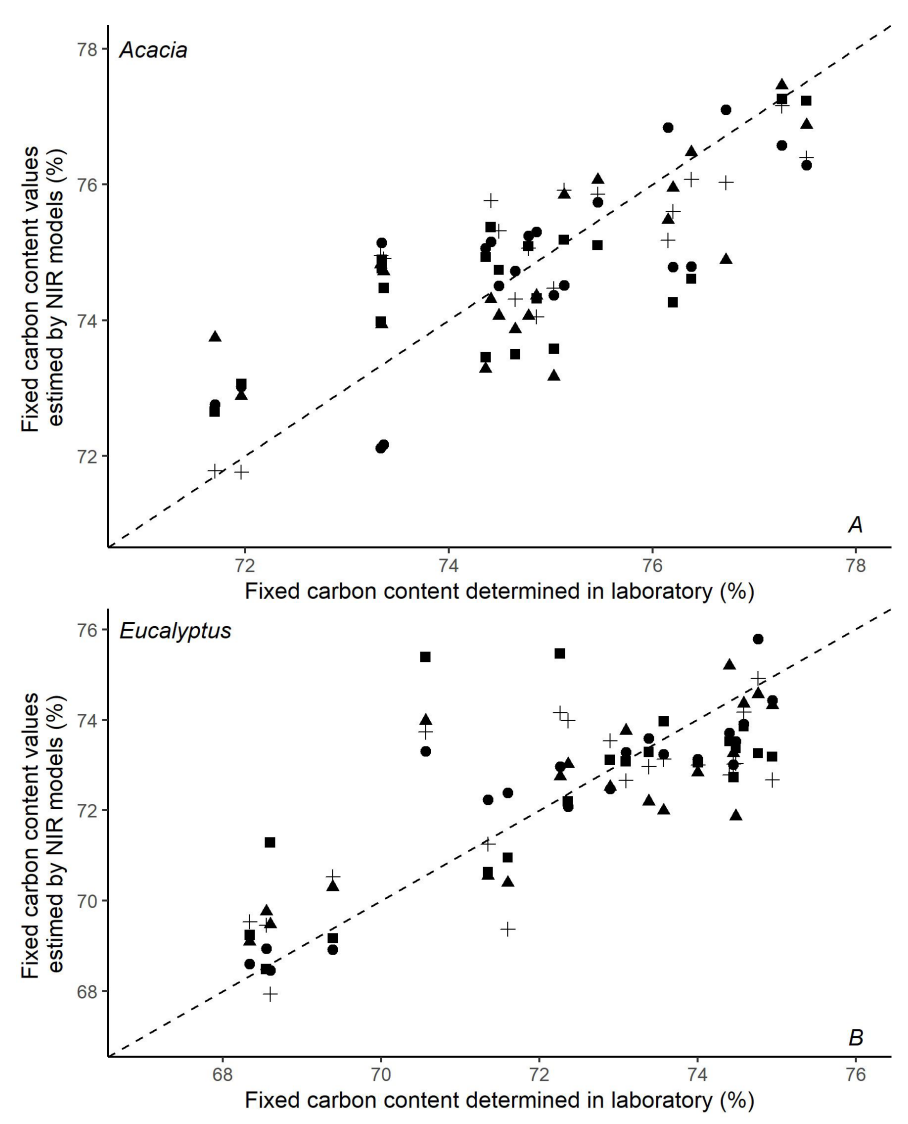

- P $\Delta 100$ - $60+40$

Figure 3. Fixed carbon content values determined in the laboratory and estimated by models based on spectra obtained on powder milled at 100,60 and 40 mesh and fine powder for Acacia (A) and Eucalyptus (B). 


\section{CONCLUSION}

The estimation of the fixed carbon content, volatile content and ash content of Eucalyptus based on NIR is more accurate when spectra are recorded in powder of lower particle size. On the other hand, the predictive models for Acacia charcoal were obtained from spectra measured in powders of 40 mesh to predict the fixed carbon content, 100 mesh for the ash content and the lowest grain size for the volatile material content.

NIR spectroscopy proved to be efficient in estimating the chemical composition of charcoal, except for ash content. In short, the PLS-R models reported in this paper are able to satisfactorily provide estimates in unknown charcoal samples.

\section{ACKNOWLEDGEMENTS}

The authors express thanks to the Wood Science and Technology Laboratory of the Federal University of Lavras (UFLA, Brazil) for supporting the experimental work, and Federal University of Minas Gerais (UFMG, Brazil) for providing vegetal material, CNPq (National Council for Scientific and Technological Development, Brazil), CAPES (Higher Education Personnel Improvement Coordination, Brazil), and FAPEMIG (Foundation for Research Support of the State of Minas Gerais, Brazil).

\section{SUBMISSION STATUS}

Received: 25 oct., 2018

Accepted: 04 dec., 2018

\section{CORRESPONDENCE TO}

\section{Fernanda Maria Guedes Ramalho}

Departamento de Ciências Florestais, Universidade Federal de Lavras - UFLA, Caixa Postal 3037, CEP 37200-000, Lavras, Minas Gerais, Brasil e-mail: fernandaguedesrm@hotmail.com

\section{FINANCIAL SUPPORT}

Fundação de Amparo à Pesquisa do Estado de Minas Gerais. Universidade Federal de Lavras. Conselho Nacional de Desenvolvimento Científico e Tecnológico, (Grant / Award Number: 405085 / 2016-8, 303675 / 2017-9 e 141427 / 2017-5). Coordenação de Aperfeiçoamento de Pessoal de Nível Superior, (Grant / Award Number: 001)

\section{REFERENCES}

Akhtar A, Krepl V, Ivanova T. A combined overview of combustion, pyrolysis, and gasification of biomass. Energy \& Fuels 2018; 32(7): 7294-7318. http://dx.doi.org/10.1021/ acs.energyfuels. $8 \mathrm{~b} 01678$.

American Society for Testing Materials - ASTM. D176284: Standard test method for chemical analysis of wood charcoal. Philadelphia: ASTM International, 2007.

Andrade CR, Trugilho PF, Hein PRG, Lima JT, Napoli A. Near infrared spectroscopy for estimating Eucalyptus charcoal properties. Journal of Near Infrared Spectroscopy 2012; 20(6): 657-666. http://dx.doi.org/10.1255/jnirs.1028.

Barbieri CCT, Osório E, Vilela ACF. Combustibility and reactivity of coal blends and charcoal fines aiming use in ironmaking. Materials Research 2016; 19(3): 594-601. http://dx.doi.org/10.1590/1980-5373-MR-2015-0705.

Barbosa ACCM, Chaix G, Davrieux F, Silva VR, Trugilho PF, Napoli A. Fecal NIR spectroscopy for the prediction of fixed carbon in Eucalyptus charcoal in steelmaking industries. In: Picking up good vibrations. NIR 2013: 16th International Conference on Near Infrared Spectroscopy; 2013; France. France: IRSTEA; 2013. p. 495-505.

Costa LR, Trugilho PF, Hein PRG. Evaluation and classification of Eucalypt charcoal quality by near infrared spectroscopy. Biomass and Bioenergy 2018; 114: 85-92. http://dx.doi.org/10.1016/j.biombioe.2018.02.017.

Davrieux F, Rousset PLA, Pastore TCM, Macedo LA, Quirino WF. Discrimination of native wood charcoal by infrared spectroscopy. Quimica Nova 2010; 33(5): 1093 1097. http://dx.doi.org/10.1590/S0100-40422010000500016.

Diesel KMF, Costa FSL, Pimenta AS, Lima KMG. Nearinfrared spectroscopy and wavelength selection for estimating basic density in Mimosa tenuiflora [Willd.] Poiret wood. Wood Science and Technology 2014; 48(5): 949-959. http://dx.doi.org/10.1007/s00226-014-0652-1.

Fahey LM, Nieuwoudt MK, Harris PJ. Using near infrared spectroscopy to predict the lignin content and monosaccharide compositions of Pinus radiata wood cell walls. International Journal of Biological Macromolecules 2018; 113: 507-514. http://dx.doi.org/10.1016/j. ijbiomac.2018.02.105. PMid:29458099.

Majumder A, Jain R, Banerjee P, Barnwal J. Development of a new proximate analysis based correlation to predict calorific value of coal. Fuel 2008; 87(13-14): 3077-3081. http://dx.doi.org/10.1016/j.fuel.2008.04.008.

Monteiro TC, Silva RV, Lima JT, Hein PRG, Napoli A. Use of near infrared spectroscopy to distinguish carbonization processes and charcoal sources. Cerne 2010; 16(3): 381-390. http://dx.doi.org/10.1590/S0104-77602010000300014.

Muniz GIB, Carneiro ME, Nisgoski S, Ramirez MGL, Magalhães WLE. SEM and NIR characterization of four forest species charcoal. Wood Science and Technology 
2013; 47(4): 815-823. http://dx.doi.org/10.1007/s00226013-0539-6.

Nisgoski S, Muniz GIB, Marrone SR, Schardosin FZ, França RF. NIR and anatomy of wood and charcoal from Moraceae and Euphorbiaceae species. Ciência da Madeira 2015a; 6(3): 183-190. http://dx.doi.org/10.12953/21776830/rcm.v6n3p183-190.

Nisgoski S, Carneiro ME, Bolzon de Muñiz GI. Influencia de la granulometria de la muestra en la discriminación de especies de Salix por infrarrojo cercano. Maderas. Ciencia y Tecnología 2015b; 17(1): 195-204. http://dx.doi. org/10.4067/S0718-221X2015005000019.

Nunes CA, Freitas MP, Pinheiro ACM, Bastos SC. Chemoface: A novel free user-friendly interface for chemometrics. Journal of the Brazilian Chemical Society 2012; 23(11): 2003-2010. http://dx.doi.org/10.1590/ S0103-50532012005000073.

Parikh J, Channiwala AS, Ghosal GK. A correlation for calculating $\mathrm{HHV}$ from proximate analysis of solid fuels. Fuel 2005; 84(5): 487-494. http://dx.doi.org/10.1016/j. fuel.2004.10.010.

Pasquini C. Near infrared spectroscopy: A mature analytical technique with new perspectives - A review.
Analytica Chimica Acta 2018; 1026: 8-36. http://dx.doi. org/10.1016/j.aca.2018.04.004. PMid:29852997.

Protásio TP, Bufalino L, Tonoli GHD, Couto AM, Trugilho PF, Guimarães M Jr. Relação entre o poder calorífico superior e os componentes elementares e minerais da biomassa vegetal. Pesquisa Florestal Brasileira 2011; 31(66): 122-133. http://dx.doi.org/10.4336/2011.pfb.31.66.113.

Ramalho FMG, Hein PRG, Andrade JM, Napoli A. Potential of near-infrared spectroscopy for distinguishing charcoal produced from planted and native wood for energy purpose. Energy \& Fuels 2017; 31(2): 1593-1599. http:// dx.doi.org/10.1021/acs.energyfuels.6b02446.

Trugilho PF, Lima JT, Mori FA, Lino AL. Avaliação de clones de Eucalyptus para a produção de carvão vegetal. Cerne 2001; 7(2): 104-114.

Vale AT, Costa AF, Gonçalves JC, Nogueira M. Relação entre a densidade básica da madeira, o rendimento e a qualidade do carvão vegetal de espécies do cerrado. Revista Árvore 2001; 25(1): 89-95.

Vilela AO, Lora ES, Quintero QR, Vicintin RA, Souza TPS. A new technology for the combined production of charcoal and electricity through cogeneration. Biomass and Bioenergy 2014; 69: 222-240. http://dx.doi.org/10.1016/j. biombioe.2014.06.019. 